\title{
Application of Response Surface Methodology to Optimize the Drying Conditions of Black Tea using a Superheated Steam Dryer
}

\author{
Rumaisa Nordin ${ }^{\mathrm{a}, \mathrm{b}}$, Norazatul H. M. Rozalli ${ }^{\mathrm{a}}{ }^{*}$, And Tajul A. Yang ${ }^{\mathrm{a}}$ \\ ${ }^{a}$ Food Technology Division, School of Industrial Technology, Universiti Sains Malaysia, 11800 Minden, Penang, \\ Malaysia \\ b Department of Chemical Engineering Technology (Food Technology), Faculty of Engineering Technology, \\ University Malaysia Perlis (UNIMAP), UNICITI Alam Campus, 02100 Sg. Chucuh, Padang Besar, Perlis, \\ Malaysia \\ ${ }^{*}$ Corresponding author \\ norazatulhanim@usm.my \\ TEL: +6046536361
}

Received: 7 August 2018; Published online: 18 October 2019

\begin{abstract}
Drying conditions of black tea using superheated steam (SHS) were optimized based on a central composite design (CCD) of response surface methodology (RSM). The effects of independent variables (temperature and time) towards the total phenolic content (TPC), scavenging free radical ability, ferric-reducing antioxidant power assay and sensory attributes (infusion colour, aroma, flavour and astringency) were analysed using regression polynomial equations. Analysis of variance (ANOVA) showed that a quadratic model fitted the experimental design well, with a p-value less than 0.05 and a highest coefficient of 0.9474 . The optimum drying conditions were achieved at $166.7^{\circ} \mathrm{C}$ and 21.2 minutes where the experimental values were in accordance with predicted values, with percentage errors $(\mathrm{PE})$ less than $10 \%$. Temperature $\left(140^{\circ} \mathrm{C}-180^{\circ} \mathrm{C}\right)$ was concluded to have the most significant effect and showed a positive direction in most responses. This effect was definitely able to support the application of a SHS dryer for the quality production (antioxidant and sensory properties) of black tea.
\end{abstract}

Keywords: Drying; Black tea; Superheated steam; Response surface methodology; Antioxidant; Sensory properties

\section{Introduction}

Tea is consumed and well-liked worldwide due to its pleasant flavour and health benefits. Black tea accounts for $80 \%$ of tea consumed in the world (Tea Fact Sheet, 2016). Special attention had been paid to processing technologies because they directly influence the quality of tea produced (Botheju, Amarathunge, \& Abeysinghe, 2011). The drying process is especially responsible for finalising the flavour of tea and removing undesired moisture to give a longer shelf life
(Kavish, S. Botheju, \& De Silva, 2016).

Drying is an energy demanding process that consumes around $10-15 \%$ of national energy in most developing countries (Mujumdar \& Devahastin, 2000). The same authors mentioned most conventional dryers use hot air that consume a large amount of energy and cause inefficiency during drying. Furthermore, traditional hot air dryers, where firewood (wooden logs) are the main source of energy, are used, especially in Kenya, Sri Lanka and Malaysia, for tea drying (Wickramasinghe \& Munasinghe, 2014). This causes 
adverse environmental impacts in terms of deforestation and air pollution (the release of carbon dioxide after burning).

SHS has been widely proposed by researchers as an effective solution to these problems in food drying. SHS is produced when saturated steam is further heated under constant pressure. SHS drying permits the recovery of the latent heat through condensation of exhaust steam, while in hot air drying this retrieval of heat in the released humid air is hard to achieve (Romdhana, Bonazzi, \& Decloux, 2015). SHS drying of food offers many advantages such as high energy efficiency (due to a higher drying rate than hot air), low net energy consumption, elimination or reduction of odour emission, oxygenfree environment (no fire and explosion hazards), lower nutrient loss and less impact on quality (colour, texture, shrinkage and rehydration) (Mujumdar, 2006). Several researchers have applied SHS drying to foodstuffs such as potatoes (Tang \& Cenkowski, 2000), cocoa beans (Zzaman, Bhat, \& Yang, 2014) and noodles (Markowski, Cenkowski, Hatcher, Dexter, \& Edwards, 2003). Previous work, done on drying mate leaves, claimed that a higher concentration of phenol content was achieved by applying SHS drying as compared with conventional hot air drying. Recently, Zzaman et al. (2014) also observed that a minimal loss of antioxidant properties and nutrients can be achieved using a SHS dryer when heat treating cocoa beans.

The effects of drying temperature and time may be vital for optimization of the processing methods used to obtain a cup of black tea with good flavour (Kaack \& P. Christensen, 2008). RSM is a powerful tool that enables optimal drying conditions to be generated with fewer experimental runs (Chakraborty, Bera, Mukhopadhyay, \& Bhattacharya, 2011). This statistical technique can also evaluate the relationship between independent and dependent variables, and describe the effects of all combined variables (Erbay \& Icier, 2009). Even with much work done, using RSM for optimization of food processes, there is a lack of literature covering the effects of drying conditions on black tea product quality using a SHS dryer. Therefore, the aim of this research is to optimize the performance of a SHS dryer for the quality production of black tea.
The quality attributes of concern are phenolic content, antioxidant ability and sensory qualities (liquid colour, aroma, flavour and astringency taste). Additionally, there are limited comprehensive studies dealing with the correlation between chemical composition, antioxidant activity and sensory attributes. Herein, this study focused on providing a better understanding of the relationship between these variables, with the aim of ultimately improving product quality in the development and production of black tea.

\section{Materials and Methods}

\subsection{Drying procedure}

Freshly fermented tea leaves $(60 \%$, moisture content), collected from the $\mathrm{BOH} \mathrm{Sg}$ Palas plantation, Cameron Highland, Malaysia, were dried using a superheated steam dryer (Healsio, AX1500 V, SHARP, Osaka, Japan). The dryer consisted of a $900 \mathrm{~W}$ steam heater and a backwardcurved blade centrifugal fan, and had a $16 \mathrm{cc} / \mathrm{min}$ steam generation power (Zzaman et al., 2014). Tea leaves were thinly spread as a single layer on a steel broil pan $(359 \times 256 \times 339 \mathrm{~mm})$. Steam generated by the boiler was continuously heated until it reached the superheated state. Once steam reached the superheated state, the SHS dryer was fully operated on pure steam. The heat was then transferred onto the product by the centrifugal fan to dry and evaporate the water. The temperature and time ranges were between $140-180^{\circ} \mathrm{C}$ and $20-25$ minutes respectively. These ranges were chosen based on preliminary results to produce tea with a moisture level of $3-4 \%$. After drying, the samples were left to cool in a desiccator at room temperature before being vacuum packed into fully metalized bags, for storage prior to analysis.

\subsection{Optimization of Superheated Steam Drying}

RSM was used to investigate the effects of two independent variables, namely temperature $\left({ }^{\circ} \mathrm{C}\right)$ and time (minutes), on seven dependent variables which are TPC, scavenging free radical, reducing power assay, and sensory attributes of tea 
Optimization of Black Tea drying using a Superheated Steam Dryer $\mid 83$

Table 1: Face centered CCD settings in the original and coded form of the independent variables $\left(\mathrm{X}_{1}\right.$, $\mathrm{X}_{2}$ ) for black tea drying using a SHS dryer

\begin{tabular}{ccccc}
\hline \multirow{2}{*}{ Runs } & \multicolumn{2}{c}{ Temperature $\left({ }^{\circ} \mathbf{C}\right)$} & \multicolumn{2}{c}{ Time $(\mathbf{m i n})$} \\
\cline { 2 - 5 } & $\begin{array}{c}\text { Coded Level } \\
\left(\mathbf{x}_{1}\right)\end{array}$ & $\begin{array}{c}\text { Actual Level } \\
\left(\mathbf{X}_{1}\right)\end{array}$ & $\begin{array}{c}\text { Coded Level } \\
\left(\mathbf{x}_{1}\right)\end{array}$ & $\begin{array}{c}\text { Actual Level } \\
\left(\mathbf{X}_{2}\right)\end{array}$ \\
\hline 1 & 1 & 180 & 1 & 25 \\
$* 2$ & 0 & 160 & 0 & 22.5 \\
$* 3$ & 0 & 160 & 0 & 22.5 \\
4 & -1 & 140 & 1 & 25 \\
5 & -1 & 140 & -1 & 20 \\
6 & 0 & 160 & 1 & 25 \\
7 & -1 & 140 & 0 & 22.5 \\
8 & 1 & 180 & 0 & 22.5 \\
9 & 0 & 160 & -1 & 20 \\
$* 10$ & 0 & 160 & 0 & 22.5 \\
11 & 1 & 180 & -1 & 20 \\
$* 12$ & 0 & 160 & 0 & 22.5 \\
$* 13$ & 0 & 160 & 0 & 22.5 \\
\hline
\end{tabular}

infusion colour, aroma, flavour and mouth astringency. The two factors $\left(\mathrm{X}_{1}\right.$ and $\left.\mathrm{X}_{2}\right)$ and three levels $(-1,0$ and 1$)$ of a face centred CCD were chosen for all the variables within the desired ranges. A total of 13 experimental runs was obtained, including five centre points in the design performed for estimation of pure error. Table 1 shows the experimental design generated using Design Expert Version 6.0.10 (Stat-Ease Inc., Minneapolis, USA). Experiments were conducted in a random order and repeated twice for the 13 runs to minimize error due to extraneous factors.

Statistical analyses were performed to evaluate an analysis of variance (ANOVA) of the data obtained. Criteria for all statistical significance followed the rule of having a $5 \%$ significant level $(\mathrm{p} \leq 0.05)$. Model adequacy was determined with a coefficient of determination $\left(\mathrm{R}^{2}\right)$ value above $80 \%$ and an insignificant lack of fit $(\mathrm{p}>0.05)$ as the best indicators for model fitting with experimental data (Myers, Anderson-Cook, \& Montgomery, 2016).

\section{$2.3 \quad$ Validation of model}

Optimum conditions to dry tea leaves using SHS were provided by RSM based on the maximum value of TPC, antioxidant activity and target scores for sensory attributes. Predicted values of all the responses were also derived from the optimum model. Under these conditions, a validation experiment was carried out to verify the adequacy of the model equation. Experimental values obtained were compared with predicted values by calculating their percentage error $(\mathrm{PE})$. The PE should be less than $10 \%$ to indicate a good fit.

$$
P E(\%)=\frac{m_{e v}-m_{p v}}{m_{e v}} \times 100
$$

where $\mathrm{m}_{e v}$ is the experimental value and $\mathrm{m}_{p v}$ is the predicted value.

\subsection{Determination of total phenolic content (TPC)}

$1 \mathrm{~g}$ of fine particles of dried black tea were extracted in $100 \mathrm{ml}$ of boiling water, with continuous swirling for 5 minutes. The Folin-Ciocalteu procedure used by Chan, Lim, and Chew (2007) 
was followed, with slight modification. Tea samples $(300 \mu \mathrm{l})$ were transferred into test tubes to be mixed with $1.5 \mathrm{ml}$ of Folin-Ciocalteu's reagent (diluted 10 times) and $1.2 \mathrm{ml}$ of sodium carbonate $(7.5 \% \mathrm{w} / \mathrm{v})$. The tubes were then left to incubate for 30 minutes at room temperature. After incubation, the absorbance reading was measured at $765 \mathrm{~nm}$ against a blank solution. TPC was expressed as Gallic acid equivalents (GAE) in $\mathrm{mg} \mathrm{GAE} / \mathrm{g}$ material.

\subsection{DPPH free-radical scavenging assay}

The 1, 1-diphenyl-2-picrylhydrazyl (DPPH) radical scavenging assay of black tea extraction was carried out in accordance with the procedure reported by Omwamba and $\mathrm{Hu}$ (2010), with slight modifications. Different dilutions of the extract were mixed with $2 \mathrm{ml}$ of DPPH $(5.9 \mathrm{mg} / 100 \mathrm{ml}$ methanol) and then incubated for 30 minutes. The absorbance reading was then taken at 516 $\mathrm{nm}$ against a control sample. The free radical scavenging ability of black tea extracts were calculated as follows:

Scavenging ability $(\%)=\left[1-\left(\frac{A_{516} \text { of sample }}{A_{516} \text { of control }}\right)\right] \times 100$

\subsection{Ferric reducing power assay}

The ferric-reducing antioxidant power (FRAP) of black tea infusion was determined according to an adapted method of Benzie and Szeto (1999). FRAP reagent was prepared by adding together $100 \mathrm{ml}$ of acetate buffer (0.3 M, pH 3.4), $10 \mathrm{ml}$ of 2,4,6-Tri (2-pyridyl)-s-triazine (TPTZ) solution in $40 \mathrm{Mm} \mathrm{HCl}$ and $10 \mathrm{ml}$ of iron (III) chloride $\left(\mathrm{FeCl}_{3} \cdot 6 \mathrm{H}_{2} \mathrm{O}\right) .4 .5 \mathrm{ml}$ of FRAP reagent was then mixed with different dilutions of the extracts. The mixture was later incubated at $37^{\circ} \mathrm{C}$ for 4 minutes before the absorbance reading was measured at $593 \mathrm{~nm}$. A standard curve of ferrous sulphate was prepared at different concentrations.

\subsection{Sensory evaluation}

The protocol for sensory evaluation in this study was approved by the Human Research Ethics Committee of University Sains Malaysia (USM). Sensory evaluation of the investigated black tea was performed by quantitative descriptive analysis according to ISO 3130 (1980). It was conducted by professional tea tasters, aged between 30-40 years old, with over 10 years' experience in tea tasting. The analysis took place at $\mathrm{BOH}$ Company, Banting, Malaysia. The sensory attributes are tea infusion colour, aroma, flavour and mouth astringency. During the quantitative assessment, the assessors evaluated the intensity of the specified attributes on a numeral ordinal 15-unit scale with the end values labelled as weak and strong. The tea samples were served in randomized order. The average scores of sensory attributes, based on the scores given by three panellists, were presented as evaluation results.

\section{$3 \quad$ Results and Discussions}

\subsection{Model fitting}

A second order polynomial equation was employed on the experimental data to obtain multiple regression analysis for each response as follows:

$\Upsilon=\beta_{0}+\beta_{1} X_{1}+\beta_{2} X_{2}+\beta_{12} X_{1} X_{2}+\beta_{11} X_{1}^{2}+\beta_{22} X_{2}^{2}$

Where $\Upsilon$ is a response variables $\left(\Upsilon_{1}=\mathrm{TPC} ; \Upsilon_{2}\right.$ $=\mathrm{DPPH}$ scavenging ability; $\Upsilon_{3}=$ FRAP metal chelating activity; $\Upsilon_{4}=$ infusion colour; $\Upsilon_{5}=$ aroma; $\Upsilon_{6}=$ flavour and $\Upsilon_{7}=$ mouthfeel (astringency) and $\beta_{0}$ is a constant coefficient of the model. Other coefficients are $\beta_{1}$ and $\beta_{2}$ (linear), $\beta_{11}$ and $\beta_{22}$ (quadratic) and $\beta_{12}$ (interaction regression). $\mathrm{X}$ represents the coded independent variables where $\mathrm{X}_{1}$ is temperature and $\mathrm{X}_{2}$ is time. The experimental data of various responses during drying of tea leaves are presented in Table 2. The ANOVA results (Table 3 ) indicate that the quadratic model is the best fit model based on its statistical significance in comparison with the linear and two-factor interaction (2FI) models for all responses. Figures 1 and 2 (a-g) show the interaction effects of drying conditions (time and 
Optimization of Black Tea drying using a Superheated Steam Dryer $\mid 85$

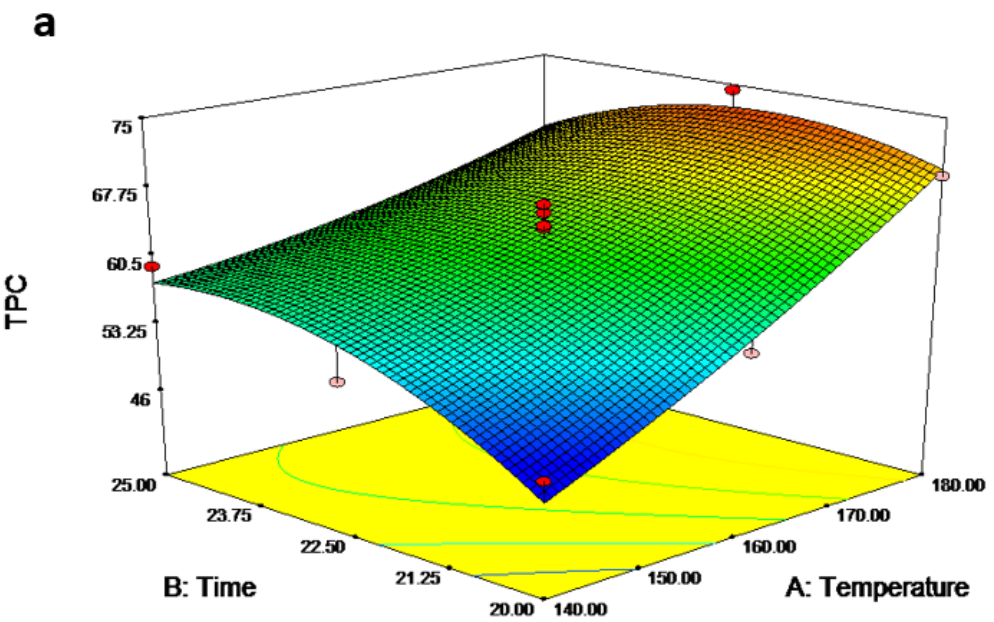

b

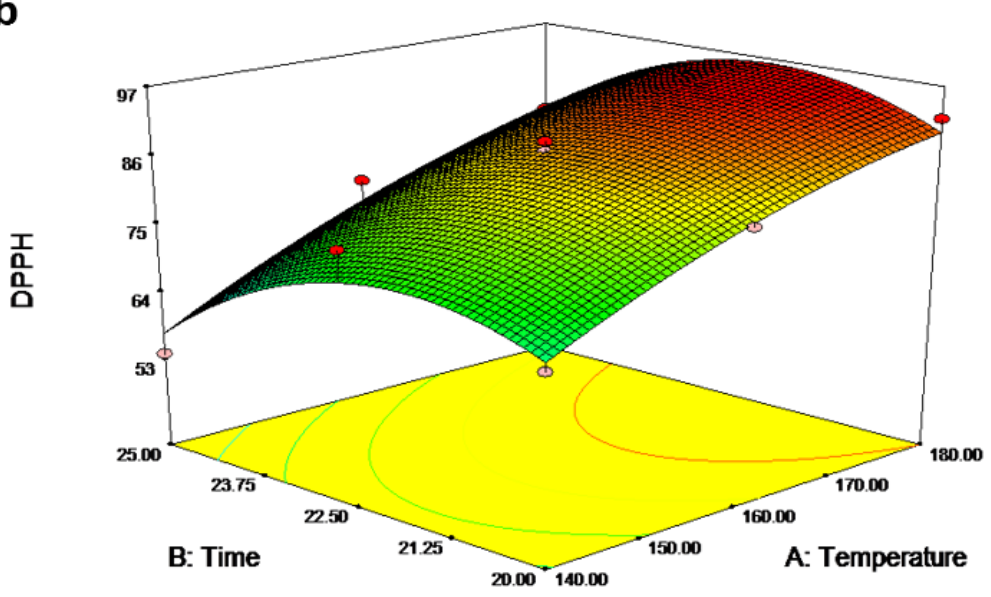

C

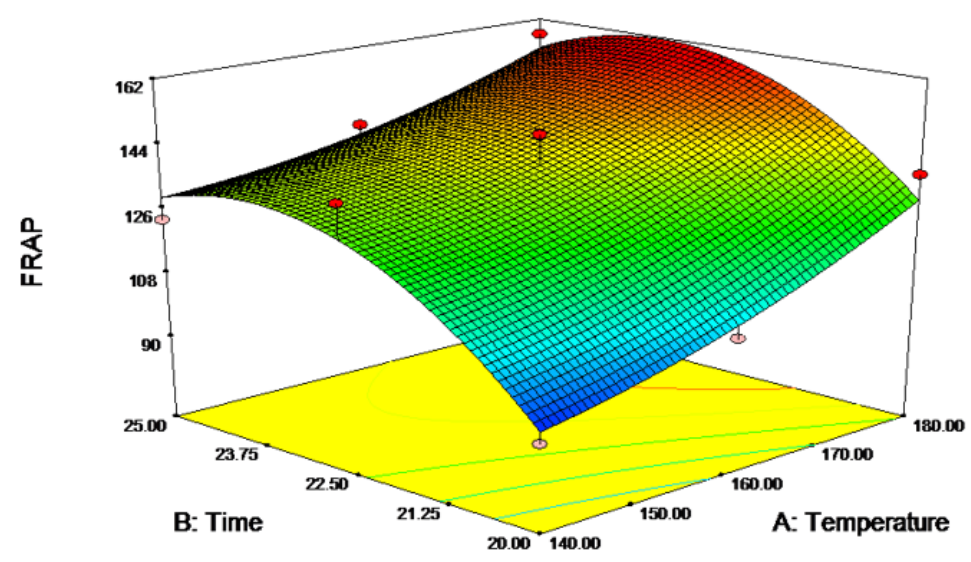

Figure 1: Response surface plots showing effects of drying temperature and time on the a) TPC, b) DPPH scavenging ability and c) FRAP 
temperature) towards each response in a contour plot. The final equations for coded factors are as follows:

$$
\begin{aligned}
& \Upsilon_{1}=62.36+8.16 X_{1}+3.62 X_{2} \\
& \Upsilon_{2}=87.39+11.21 X_{1}-5.05 X_{2} \\
& \Upsilon_{3}=140.33+14.91 X_{1}+15.23 X_{2} \\
& \Upsilon_{4}=9.93+2.61 X_{1}+1.03 X_{2} \\
& \Upsilon_{5}=6.52-0.79 X_{2} \\
& \Upsilon_{6}=7.83+2.17 X_{1} \\
& \Upsilon_{7}=8.92+2.29 X_{1}
\end{aligned}
$$

\subsection{Effect of drying conditions on TPC}

A major proportion of black tea comprises total phenolic compounds which are mostly responsible for the health effects and sensory characteristics of black tea (Luczaj \& Skrzydlewska, 2005). In the present study, the initial value of TPC before drying was $42.15 \mathrm{mg} / \mathrm{g}$ (dry basis) and the TPC values of dried black tea using a SHS dryer at different temperatures and times were in the range 805.0 to $1096.0 \mathrm{mg} / \mathrm{g}$ (dry basis). Undried tea leaves have the lowest TPC, primarily due to the presence of enzymes that might degrade the antioxidants (Roshanak, Rahimmalek, \& Goli, 2016). Dried tea leaves (3-4\% moisture ratio) retain high phenolic compounds as result of decreased water content that deactivates enzymes that might degrade phenolic compounds (Rabeta \& Lai, 2013). It is also interesting to point out that the TPC value in black tea from this study is $10 \%$ higher than those reported in the literature for conventional hot air drying (Chan et al., 2007). Loss of TPC in hot air and microwave drying may be due to the heat generated that allows oxidative condensation to take place within the system, thereby degrading polyphenols or even converting them into non-antioxidant forms (Lim \& Murtijaya, 2007).

In the present investigation, the variable $\mathrm{X}_{1}$ (temperature) was found to be highly significant with a p-value of 0.0009 followed by $\mathrm{X}_{2}$ (time) with $\mathrm{p}<0.05$. However, the other models $\left(\mathrm{X}_{12}\right.$, $\mathrm{X}_{1^{2}}$ and $\mathrm{X}_{2^{2}}$ ) were not significant for the prediction of TPC in black tea as a result of dry- ing (Table 3). The three dimensional (3D) surface plot (Figure 1-a) clearly shows an increase in TPC from $483.0 \mathrm{mg} / \mathrm{g}$ to $743.7 \mathrm{mg} / \mathrm{g}$ when increasing drying temperature from $140-180^{\circ} \mathrm{C}$. At all drying temperatures, the TPC only increased during the first 22.5 minutes and then slowly decreased after that drying time to $657.6 \mathrm{mg} / \mathrm{ml}$. This suggests that high drying temperature accelerates the release of phenolic compounds, by breaking down the cell walls of the tea leaves, making them largely accessible by the extraction method (Tomaino, Cimino, Zimbalatti, Venuti, \& De Pasquale, 2005). Indeed, TPC increased even at the highest temperature which indicates SHS can operate in the absence of oxygen thereby retaining the antioxidants, vitamins and other essential nutrients (Cenkowski, Pronyk, Zmidzinska, \& Muir, 2007). However, a prolonged exposure of heat can result in loss of TPC. A similar trend was observed in a study carried out by Temple, Temple, van Boxtel, and Clifford (2001) that proved rapid drying is vital to prevent the loss of TPC.

\subsection{Effects of drying conditions on DPPH}

Black tea mostly consists of phenolic compounds that are capable of scavenging free radicals as effectively as green tea. In the present study, the ANOVA results of DPPH verify that drying temperature and time are statistically significant $(\mathrm{p}<0.0005)$ for antioxidant activity in black tea dried using SHS (Table 3). Figure 1$\mathrm{b}$ depicts the 3D representation of the response surface that shows the influence of the independent variables on DPPH radical scavenging activity. SHS drying temperature significantly increased the antioxidant activities of black tea (53\% - 93\%), whereas a longer duration of drying caused the activities to decrease. Among the conditions, drying temperature and time of $180^{\circ} \mathrm{C}$ and 22.5 minutes respectively provided the highest percentage of DPPH radical scavenging activity, which coincides with the TPC assay. These findings indicate that antioxidant ability is highly related to TPC as these compounds can act as free radical scavengers during oxidation reactions (Youssef \& Mokhtar, 2014). 
Optimization of Black Tea drying using a Superheated Steam Dryer $\mid 87$

Table 2: Experimental values of TPC (mg/g), DPPH (\%), FRAP (mg/g) and sensory attributes of dried tea leaves using a SHS dryer

\begin{tabular}{cccccccc}
\hline Run & TPC $(\mathbf{m g} / \mathbf{g})$ & DPPH $(\mathbf{\%})$ & FRAP $(\mathbf{m g} / \mathbf{g})$ & Liquor colour & Aroma & Flavour & Mouthfeel \\
\hline 1 & 804.95 & 68.23 & 150.06 & 5.50 & 8.25 & 7.00 & 8.00 \\
2 & 873.10 & 78.32 & 232.02 & 6.50 & 7.00 & 7.00 & 7.75 \\
3 & 990.76 & 53.85 & 205.36 & 7.00 & 6.25 & 7.75 & 8.00 \\
4 & 922.61 & 81.80 & 171.79 & 7.25 & 7.25 & 8.50 & 9.50 \\
5 & 1063.20 & 84.02 & 244.76 & 10.50 & 6.67 & 8.25 & 9.00 \\
6 & 1085.15 & 88.51 & 217.98 & 10.00 & 7.00 & 9.25 & 10.00 \\
7 & 1100.66 & 86.52 & 245.18 & 9.50 & 6.83 & 7.25 & 9.75 \\
8 & 1058.91 & 88.42 & 218.75 & 8.50 & 6.50 & 5.75 & 6.50 \\
9 & 996.70 & 86.84 & 245.00 & 10.50 & 5.50 & 6.50 & 8.75 \\
10 & 1009.08 & 75.73 & 232.68 & 10.25 & 6.00 & 11.50 & 9.75 \\
11 & 1149.67 & 91.94 & 226.37 & 9.50 & 7.50 & 9.25 & 11.75 \\
12 & 1239.44 & 93.64 & 247.74 & 14.00 & 7.00 & 12.50 & 12.75 \\
13 & 1096.04 & 82.09 & 262.44 & 11.17 & 6.00 & 13.00 & 13.00 \\
\hline
\end{tabular}
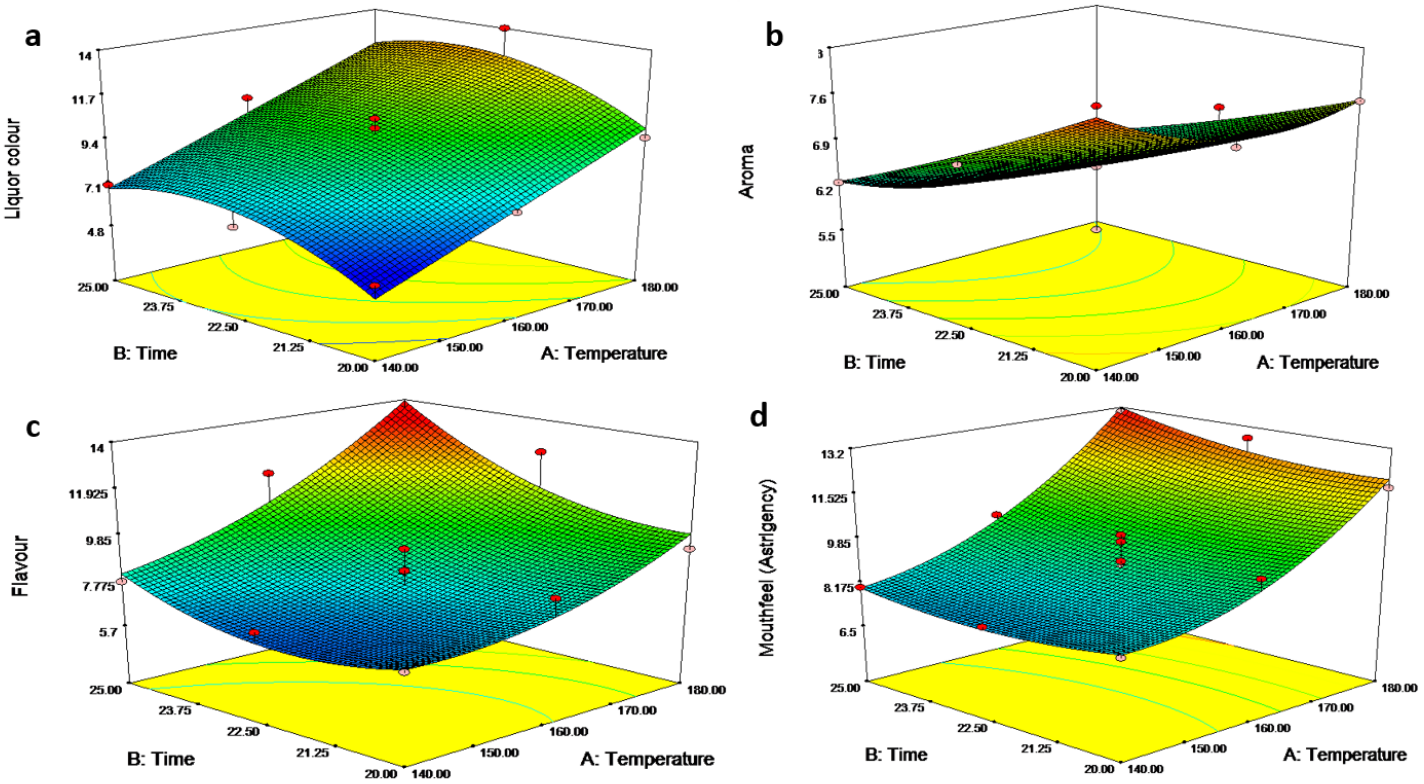

Figure 2: Response surface plots for the effects of drying temperature and time on sensory attributes of dried black tea extracts: a) liquor colour, b) aroma, c) flavour and d) mouthfeel (astringency) 
88 Nordin et al.

Table 3: Summary for quadratic, linear and interaction model analysis, lack of fit and $\mathrm{R}^{2}$ for measured responses

\begin{tabular}{lccccccccc}
\hline Source & \multicolumn{9}{c}{ Response variables } \\
\cline { 2 - 9 } & \multicolumn{3}{c}{ TPC } & \multicolumn{3}{c}{ DPPH } & \multicolumn{3}{c}{ FRAP } \\
\cline { 2 - 9 } & Quadratic & Linear & 2FI & Quadratic & Linear & 2FI & Quadratic & Linear & 2 FI \\
\hline $\mathrm{R}^{2}$ & 0.8403 & 0.8184 & 0.8326 & 0.9474 & 0.6491 & 0.6528 & 0.8511 & 0.6255 & 0.6332 \\
Prob. $>\mathrm{F}$ & 0.0103 & 0.0002 & 0.0008 & 0.0014 & 0.0053 & 0.0187 & 0.0426 & 0.0074 & 0.0237 \\
Lack of fit & 0.1013 & 0.2021 & 0.1830 & 0.0578 & 0.0043 & 0.0032 & 0.3449 & 0.1622 & 0.1310 \\
\hline
\end{tabular}

\begin{tabular}{|c|c|c|c|c|c|c|c|c|c|c|c|c|}
\hline \multirow[t]{3}{*}{ Source } & \multicolumn{12}{|c|}{ Response variables } \\
\hline & \multicolumn{3}{|c|}{ Liquor colour } & \multicolumn{3}{|c|}{ Aroma } & \multicolumn{3}{|c|}{ Flavour } & \multicolumn{3}{|c|}{ Mouthfeel (astringency) } \\
\hline & Quadratic & Linear & $2 \mathrm{FI}$ & Quadratic & Linear & $2 \mathrm{FI}$ & Quadratic & Linear & $2 \mathrm{FI}$ & Quadratic & Linear & $2 \mathrm{FI}$ \\
\hline $\mathrm{R}^{2}$ & 0.8727 & 0.7584 & 0.7585 & 0.7501 & 0.6270 & 0.6370 & 0.7570 & 0.5872 & 0.6224 & 0.8157 & 0.7000 & 0.7086 \\
\hline Prob. $>\mathrm{F}$ & 0.0049 & 0.0008 & 0.0039 & 0.0438 & 0.0072 & 0.0227 & 0.0401 & 0.0120 & 0.0268 & 0.0166 & 0.0024 & 0.0088 \\
\hline Lack of fit & 0.2041 & 0.1597 & 0.1243 & 0.9111 & 0.8140 & 0.7608 & 0.3755 & 0.3338 & 0.3120 & 0.9404 & 0.7740 & 0.7175 \\
\hline
\end{tabular}

\subsection{Effects of drying conditions on FRAP}

Antioxidant properties are also associated with the ability of phenolic compounds to form complexes with metal ions. In the present study, reducing capabilities of black tea extracts, undergoing different drying conditions, were in the range 150.1 to $262.4 \mathrm{mg} / \mathrm{g}$ (dry basis). From statistical measurements shown in Table 4, it was concluded that both temperature and time significantly affect the metal chelating ability of dried black tea $(\mathrm{p}<0.01)$. The contour plot (Figure 1-c) also showed that the reducing power of black tea increased as temperature increased. This trend was also observed with the DPPH scavenging ability assay, where the highest reducing power was attained at $180^{\circ} \mathrm{C}$ and 22.5 minutes, while a prolonged drying time reduced both activities. Reducing capability at the highest temperature could be explained due to the fact that novel antioxidant compounds may be formed from Maillard reaction products (Manzocco, Anese, \& Nicoli, 1998). In addition, an oxygen free environment in SHS also promotes the preservation of antioxidant compounds and reduces any oxidation reaction taking place.

In absolute terms, the three major parameters of TPC, free radical scavenging ability and FRAP are all interconnected between one another. They are highly affected by the drying conditions used with positive direction.

\subsection{Effects of drying conditions on sensory attributes}

The taste quality of black tea largely depends on its liquid colour, brightness, appearance, aroma, flavour and mouthfeel (astringency) (Tea Manufacturing, 2016). Primarily, liquid colour is an important factor not only in assessing the visual aspect of tea infusion but also for its relationship with antioxidant content (Ratti, 2001). Results clearly show that drying temperature and time largely affect the infusion colour of black tea extract. Specifically shown in Figure 2-a, the intensity of infusion colour of black tea increased with drying temperature and time. This result corroborates the work done by Teshome, Debela, and Garedew (2014) where the higher temperature and increase in drying time of tea leaves led to the loss of brightness and the tea infusion became darker and dull. This also hinted that the Maillard reaction (browning) occurred which may result in antioxidant ability during drying of black tea (Lou et al., 2015).

In the case of black tea aroma, only the single interaction of drying time can affect aroma scores with $\mathrm{p}<0.05$ (Table 4). Figure 2-b clearly shows the effect of drying time on the aroma of tea infusions. At longer drying time, the aroma of tea

IJFS | October 2019 | Volume 8 | pages 81-92 
Optimization of Black Tea drying using a Superheated Steam Dryer $\mid 89$

Table 4: ANOVA evaluation of quadratic terms for response variables of TPC, DPPH, FRAP and sensory properties

\begin{tabular}{|c|c|c|c|c|c|c|c|c|c|}
\hline \multirow[t]{3}{*}{ Source } & \multicolumn{9}{|c|}{ Response variables } \\
\hline & \multicolumn{3}{|c|}{ TPC } & \multicolumn{3}{|c|}{ DPPH } & \multicolumn{3}{|c|}{ FRAP } \\
\hline & $\begin{array}{l}\text { Sum of } \\
\text { squares }\end{array}$ & F value & p-value & $\begin{array}{l}\text { Sum of } \\
\text { squares }\end{array}$ & F value & p-value & $\begin{array}{l}\text { Sum of } \\
\text { squares }\end{array}$ & F value & p-value \\
\hline Model & 491.31 & 7.37 & 0.0103 & 1324.36 & 25.21 & 0.0002 & 3707.89 & 8.00 & 0.0082 \\
\hline A & 399.84 & 29.98 & 0.0009 & 754.32 & 71.81 & $<0.0001$ & 1333.98 & 14.40 & 0.0068 \\
\hline B & 78.65 & 5.90 & 0.0455 & 153.05 & 14.57 & 0.0066 & 1391.02 & 15.01 & 0.0061 \\
\hline $\mathrm{AB}$ & 8.30 & 0.62 & & 5.15 & 0.49 & & 33.27 & 0.36 & \\
\hline $\mathrm{A}^{2}$ & $4.82 \times 10^{-3}$ & $3.623 \times 10^{-4}$ & & 20.78 & 1.98 & & 50.54 & 0.55 & \\
\hline $\mathrm{B}^{2}$ & 3.75 & 0.28 & & 273.82 & 26.07 & 0.0041 & 926.10 & 10.00 & 0.0159 \\
\hline Residual & 93.35 & & & 73.53 & & & 342.32 & & \\
\hline $\mathrm{CV}(\%)$ & $5.91 \%$ & & & $3.98 \%$ & & & $7.19 \%$ & & \\
\hline
\end{tabular}

\begin{tabular}{|c|c|c|c|c|c|c|c|c|c|c|c|c|}
\hline \multirow[t]{3}{*}{ Source } & \multicolumn{12}{|c|}{ Response variables } \\
\hline & \multicolumn{3}{|c|}{ Liquor colour } & \multicolumn{3}{|c|}{ Aroma } & \multicolumn{3}{|c|}{ Flavour } & \multicolumn{3}{|c|}{ Mouthfeel } \\
\hline & $\begin{array}{l}\text { Sum of } \\
\text { quares }\end{array}$ & F value & p-value & $\begin{array}{l}\text { Sum of } \\
\text { squares }\end{array}$ & F value & p-value & $\begin{array}{l}\text { Sum of } \\
\text { squares }\end{array}$ & F value & p-value & $\begin{array}{l}\text { Sum of } \\
\text { squares }\end{array}$ & F value & p-value \\
\hline Model & 54.37 & 9.60 & 0.0049 & 4.70 & 4.20 & 0.0438 & 48.40 & 4.36 & 0.0401 & 37.15 & 6.20 & 0.0166 \\
\hline A & 40.91 & 36.11 & 0.0005 & 0.17 & 0.75 & & 28.17 & 12.69 & 0.0092 & 31.51 & 26.27 & 0.0014 \\
\hline B & 6.34 & 5.60 & 0.0499 & 3.76 & 16.82 & 0.0046 & 9.37 & 4.22 & & 0.37 & 0.31 & \\
\hline $\mathrm{AB}$ & $6.944 \times 10^{-3}$ & $6.13 \times 10^{-3}$ & & 0.0063 & 0.28 & & 2.25 & 1.01 & & 0.39 & 0.33 & \\
\hline $\mathrm{A}^{2}$ & $3.649 \times 10^{-4}$ & $3.22 \times 10^{-4}$ & & 0.53 & 2.39 & & 2.01 & 0.91 & & 2.88 & 2.40 & \\
\hline $\mathrm{B} 2$ & 6.12 & 5.40 & & 0.012 & 0.052 & & 3.36 & 1.52 & & 0.43 & 0.36 & \\
\hline Residual & 7.93 & & & 1.57 & & & 15.54 & & & 8.40 & & \\
\hline CV (\%) & $11.51 \%$ & & & $7.01 \%$ & & & $17.06 \%$ & & & 11.44 & & \\
\hline
\end{tabular}

infusion scores dropped from 8.5 to 5.5 . This behavior can be explained due to the evaporation of volatile compounds responsible for tea aroma (Tuan, Thinh, \& Tu, 2016). Besides that, mishandling tea when all samples were prepared in one go for tasting could cause loss of aroma and inconsistent scores. Therefore, two or three sessions of tea tasting are suggested to be conducted to avoid the loss of aroma.

Both flavour and mouthfeel are only affected by temperature. Figure 2-c and 2-d show similarity between these two quality attributes as temperature increased, whereby the strength of flavour and mouthfeel also increased. The highest scores for both characteristics were achieved at $180^{\circ} \mathrm{C}$ after 25 minutes of drying using a SHS dryer. In terms of flavour formation in black tea infusion, it is highly dependent on the content of essential oils in tea leaves that are strongly affected by temperature (Ho, Zheng, \& Li, 2015). In contrast, the astringent taste in black tea was re- ported to be closely related to the theaflavins and thearubigins components (Scharbert, Jezussek, \& Hofmann, 2004). Nevertheless, the key to good quality of black tea extracts is the balanced taste in terms of strength of flavour and the astringent and bitter taste (Scharbert et al., 2004). Thus, having a strong flavour can lead to a high bitter taste which results in loss of a balanced flavour in black tea (Wang et al., 2014).

\subsection{Optimization and validation}

A simultaneous multiple response optimization was employed to generate the optimum process conditions for SHS dying of black tea. Specific criteria of having maximum value of TPC and antioxidant ability, and a set target score of 7.5 for all sensory characteristics were assigned (Table 5). The target score for all sensory characteristics was set following the reference standard that was commercialized and accepted by con- 
$90 \mid$ Nordin et al.

Table 5: Comparison of experimental and predicted values for all responses of dried tea leaves using a SHS dryer, with PE calculated

\begin{tabular}{lcccc}
\hline Name & Predicted value & Actual value & Relative difference & Percentage Error (\%) \\
\hline TPC (mg/g) & 1142.20 & 1100.60 & 1.04 & 3.71 \\
DPPH (\%) & 89.90 & 88.51 & 1.02 & 1.56 \\
FRAP (mg/g) & 233.23 & 217.90 & 1.07 & 6.80 \\
Liquor colour & 9.50 & 10.00 & 0.95 & 5.13 \\
Aroma & 6.80 & 6.50 & 1.05 & 4.51 \\
Flavour & 8.90 & 8.20 & 1.09 & 8.19 \\
Astringency & 9.95 & 9.75 & 1.02 & 2.03 \\
\hline
\end{tabular}

sumers.

The optimal experimental conditions for the drying of black tea using SHS was found to be at $166.7^{\circ} \mathrm{C}$ and 21.2 minutes with a desirability of $71.8 \%$. Predicted values of each response were estimated to be $644.4 \mathrm{mg} / \mathrm{g}$ for TPC, $90.6 \%$ scavenging free radical ability, $133.3 \mathrm{mg} / \mathrm{g}$ for its reducing power and scores of 9.8, 7, 8.3 and 9.7 for tea infusion colour, aroma, and flavour and astringency levels respectively. Verification of the model was conducted. The percentage error calculated was not more than $10 \%$ of experimental data difference from predicted value thus confirming the suitability of the optimal conditions produced from the RSM.

\section{Conclusion}

RSM is a powerful tool that was successfully used in the present study to perform an optimization of drying conditions for black tea. The contour plot clearly visualized the interaction between all variables for the response of quality attributes in black tea drying. The optimal experimental conditions for the drying of black tea using SHS were found to be $166.7^{\circ} \mathrm{C}$ and 21.2 minutes. Drying temperature is the most significant factor that affects TPC, antioxidant ability and sensory scores. The present results highlighted the drying approach of SHS is effective in preserving the antioxidant compounds and other quality aspects in black tea even at elevated temperature. Consequently, this study can help tea industries to consider this drying technique to retain quality aspects of their production, especially for black tea.

\section{Acknowledgements}

Authors would like to acknowledge Short Term Grant Universiti Sains Malaysia (304/PTEKIND/6313331) for funding this project, Ministry of Education of Malaysia and Universiti Malaysia Perlis for their scholarship under Bumiputera Academic Training Scheme (SLAB/SLAI).

\section{References}

Benzie, I. F. F., \& Szeto, Y. T. (1999). Total antioxidant capacity of teas by the ferric reducing/antioxidant power assay. 47, 633636.

Botheju, W., Amarathunge, K., \& Abeysinghe, I. (2011). Simulation of trough withering of tea using one dimensional heat and mass transfer finite difference model. 22.

Cenkowski, S., Pronyk, C., Zmidzinska, D., \& Muir, W. E. (2007). Decontamination of food products with superheated steam. 83, 68-75.

Chakraborty, R., Bera, M., Mukhopadhyay, P., \& Bhattacharya, P. (2011). Prediction of optimal conditions of infrared assisted freezedrying of aloe vera ( aloe barbadensis) using response surface methodology. 80, 375384.

Chan, E., Lim, Y., \& Chew, Y. L. (2007). Antioxidant activity of camellia sinensis leaves and tea from a lowland plantation in malaysia. 102, 1214-1222. 
Optimization of Black Tea drying using a Superheated Steam Dryer $\mid 91$

Erbay, Z., \& Icier, F. (2009). Optimization of hot air drying of olive leaves using response surface methodology. 91, 533-541.

Ho, C.-T., Zheng, X., \& Li, S. (2015). Tea aroma formation. 4 .

Kaack, K., \& P. Christensen, L. (2008). Effect of packing materials and storage time on volatile compounds in tea processed from flowers of black elder ( sambucus nigra 1.) 22\%, 1259-1273.

Kavish, S., S. Botheju, W., \& De Silva, C. (2016). Impact of inlet drying temperature in endless chain pressure dryers on the quality characteristics of leafy type of tea produced using different leaf standards. 10, 73 .

Lim, Y., \& Murtijaya, J. (2007). Antioxidant properties of phyllanthus amarus extracts as affected by different drying methods. 40, 1664-1669.

Lou, S.-N., Lai, Y.-C., Huang, J., Ho, C., A. Ferng, L.-H., \& Chang, Y.-C. (2015). Drying effect on flavonoid composition and antioxidant activity of immature kumquat. 171, 356-363.

Luczaj, W., \& Skrzydlewska, E. (2005). Antioxidant properties of black tea. 40, 910-8.

Manzocco, L., Anese, M., \& Nicoli, M. C. (1998). Antioxidant properties of tea extracts as affected by processing. 31, 694-698.

Markowski, M., Cenkowski, S., Hatcher, D., Dexter, J. E., \& Edwards, N. M. (2003). The effect of superheated-steam dehydration kinetics on textural properties of asian noodles. 46 .

Mujumdar, A. S. (2006). Handbook of industrial drying. CRC press.

Mujumdar, A. S., \& Devahastin, S. (2000). Fundamental principles of drying. In Mujumdar's practical guide to industrial drying: Principles, equipment and new developments (pp. 1-22). Exergex, Brossard, Canada.

Myers, R. H., Anderson-Cook, C. M., \& Montgomery, D. C. (2016). Wiley series in probability and statistics: Response surface methodology: Process and product optimization using designed experiments. Wiley: Somerset, NJ, USA.

Omwamba, M., \& Hu, Q. (2010). Antioxidant activity in barley (hordeum vulgare l.) grains roasted in a microwave oven under conditions optimized using response surface methodology. 75, C66-73.

Rabeta, M. S., \& Lai, S. Y. (2013). Effects of drying, fermented and unfermented tea of ocimum tenuiflorum linn. on the antioxidant capacity. International Food Research Journal, 20(4), 1601.

Ratti, C. (2001). Hot air and freeze-drying of high-value foods: A review. 49, 311-319.

Romdhana, H., Bonazzi, C., \& Decloux, M. (2015). Superheated-steam drying: An overview of pilot and industrial dryers with a focus on energy efficiency. 33.

Roshanak, S., Rahimmalek, M., \& Goli, S. A. H. (2016). Evaluation of seven different drying treatments in respect to total flavonoid, phenolic, vitamin c content, chlorophyll, antioxidant activity and color of green tea (camellia sinensis or c. assamica) leaves. Journal of food science and technology, 53(1), 721-729.

Scharbert, S., Jezussek, M., \& Hofmann, T. (2004). Evaluation of the taste contribution of theaflavins in black tea infusions using the taste activity concept. 218, 442-447.

Tang, Z., \& Cenkowski, S. (2000). Dehydration dynamics of potatoes in superheated steam and hot air. 42.

Tea Fact Sheet. (2016). Retrieved from http:// www.teausa.com/14655/tea-fact-sheet

Tea Manufacturing. (2016). Retrieved from http: / / www . upasitearesearch . org / tea manufacturing/

Temple, S. J., Temple, C. M., van Boxtel, T., \& Clifford, M. (2001). The effect of drying on black tea quality. $81,764-772$.

Teshome, K., Debela, A., \& Garedew, W. (2014). Effect of drying temperature and duration on biochemical composition and quality of black tea (camellia sinensis 1.) o. kuntze at wush wush, south western ethiopia. 12, 235-240.

Tomaino, A., Cimino, F., Zimbalatti, V., Venuti, V., V .and Sulfaro, \& De Pasquale, Y. ., A. anSzeto. (2005). Influence of heating on antioxidant activity and the chemical composition of some spice essential oils. 89, 549-554. 
Tuan, H. Q., Thinh, N. D., \& Tu, N. T. M. (2016). Effect of drying temperature on the volatile composition of orthodox black tea. Journal of Vietnam Agricultural Science and Technology, 14 (10), 1485-1490.

Wang, K., Chen, Q., Lin, Y., Li, S., Lin, H., Huang, J., \& Liu, Z. (2014). Comparison of phenolic compounds and taste of chinese black tea. 20, 639-646.

Wickramasinghe, T. A., \& Munasinghe, S. K. (2014). Energy efficiency improvement of tea driers in sri lanka.

Youssef, K. M., \& Mokhtar, S. (2014). Effect of drying methods on the antioxidant capacity, color and phytochemicals of portulaca oleracea l. leaves. 04 .

Zzaman, W., Bhat, R., \& Yang, T. (2014). Application of response surface methodology to optimize roasting conditions in cocoa beans subjected to superheated steam treatments in relevance to antioxidant compounds and activities. 32. 